\title{
PET incelemede insidental saptanan fokal kolon tutulumu olgularımız
}

\author{
Incidentally detected focal colonic involvement in our cases with PET scan
}

Serdal ÇAKMAK ${ }^{1}$, Aliye SOYLU ${ }^{1}$, Isa SEVINDIR ${ }^{1}$, Yıldız OKUTURLAR ${ }^{2}$, Mustafa UÇAR ${ }^{2}$

Bakırköy Dr. Sadi Konuk Eğitim ve Araştırma Hastanesi ${ }^{1}$ Gastroenteroloji Kliniği, ${ }^{2} I c ̧$ Hastalkklan Kliniği, Istanbul

\begin{abstract}
Giriş ve Amaç: Pozitron emisyon tomografi/bilgisayarlı tomografi'nin senkron kolonik lezyonların saptanmasında yeterli olduğu ve kolondaki florodeoksiglukoz tutulumunun önemi son çalışmalarla gösterilmiştir. Bu nedenle başka tanılarla çekilen pozitron emisyon tomografi/bilgisayarlı tomografi'de saptanan insidental fokal lezyonların sıkı olarak tetkik edilmesi önerilmektedir. Kolonda fokal florodeoksiglukoz tutulumu saptanan hastalar da kolonoskopi ve histopatolojik olarak değerlendirilmelidir. Bu çalışmanın amacı florodeoksiglukoz-pozitron emisyon tomografi/bilgisayarlı tomografi'de insidental fokal kolonik aktivite saptanan ve kolonoskopi yapılan vakalarda eşlik eden kolonik lezyon olup olmadığını ve varlığında karakterini dökümante etmektir. Gereç ve Yöntem: Farklı bir malignitenin takibi nedeniyle uygulanan pozitron emisyon tomografi/bilgisayarl tomografi'de insidental kolonik fokal tutulumu olan toplam 6 olgu çalıșmaya dahil edildi. Hastalara pozitron emisyon tomografi/bilgisayarlı tomografi bulgularmnn etiyolojisini saptamak için total kolonoskopi yapıldı. Hastalarda saptanan tüm kolonik lezyonlar endoskopik olarak çıkarıldı. Lezyonların karakteri histopatolojik inceleme ile tespit edildi. Bulgular: Fokal tutuluma neden olan poliplerin tümünün çapı $\geq 15 \mathrm{~mm}$ idi. Yüksek dereceli displazi içeren 4 polipin çapı $\geq 25 \mathrm{~mm}$ idi. Diğer poliplerden biri $20 \mathrm{~mm}$ çapında olup tübüler adenom, diğeri ise $15 \mathrm{~mm}$ çapında olup düşük dereceli displazi saptandı. Tüm olguların ikisinde ek olarak 6-7 mm çapında toplam 5 adet adenomatöz polip saptandı. Bu 5 adet polipin histopatolojik değerlendirmesinde displazi yoktu. Bu poliplere uyan florodeoksiglukoz tutulumu saptanmadı. Sonuç: Pozitron emisyon tomografi/bilgisayarlı tomografi'de insidental kolonik fokal tutulum olan alanlarda adenomatöz polipler saptanabilmektedir. Insidental tespit edilen fokal hipermetabolik durumlar göz ardı edilmemeli, teyidi ve çıkarılması için kolonoskopi yapılmalıdır. Kolon kanseri taramasında ve sürveyansinda pozitron emisyon tomografi/bilgisayarlı tomografi'nin yerini araştıran karşıllaştırmalı çalış̧malara ihtiyaç vardır.
\end{abstract}

Anahtar kelimeler: Pozitron emisyon tomografi, florodeoksiglikoz, polip

\section{GİRISŞ}

Pozitron emisyon tomografi (PET) malign tümörlerin varlığını araştıran noninvaziv fonksiyonel bir görüntüleme tekniğidir. Florodeoksiglikoz (FDG) ile PET tümörün tanısını, evrelemesini, tedaviye yanıtını belirlemekte, tümör agresifliğini ortaya koymakta ve radyoterapi alanını tespit etmekte etkin rol oynamaktadır. FDG normal dokuya göre tümörlerde yüksek konsantrasyonda tutulur ve FDG-PET imajlarında yüksek sayım veren odaklar olarak kolayca tespit edilir. Kişiden kişiye değişmekle birlikte bağırsaklarda fizyolojik olarak diffüz veya segmenter kolon tutulumları olabilir.

Farklı bir amaçla yapılan PET incelemede yüksek hassasiyeti nedeniyle GIS'te saptanan fokal veya nodüler hipermetabolik lezyonların, hiperplastik polip, villöz adenom ya da karsinom gibi premalign/malign lezyon çıkma olasılığının yüksek oldu-
Background and Aims: Recent studies have assessed the ability of positron emission tomography/computed tomography to detect synchronous colonic pathology and determined the significance of fluorodeoxyglucose activity. Therefore, focal lesions should be followed closely. In our patients with focal involvement, the diagnosis was confirmed by colonoscopy and histopathology. The aim of this case-based study was to assess the performance of fluorodeoxyglucose positron emission tomography/computed tomography for the detection of colonic adenomas. Materials and Methods: A total of six random cancer patients who underwent positron emission tomography/ computed tomography and showed intense focal colonic fluorodeoxyglucose uptake were enrolled in this study. The etiology of positron emission tomographyfindings was verified with a subsequent colonoscopy and endoscopic resection. The characteristics of the lesions detected by histopathologic examination are presented. Results: All polyps with fluorodeoxyglucose uptake were $>15 \mathrm{~mm}$. Four polyps with high-grade dysplasia were $>25 \mathrm{~mm}$ in diameter. One of the other polyps measuring $20 \mathrm{~mm}$ was determined as tubular adenoma. Another showed low-grade dysplasia and measured 15 $\mathrm{mm}$ in diameter. In addition, five adenomatous polyps 6-7 $\mathrm{mm}$ in diameter were detected in two cases. There was no dysplasia in these five polyps, and no fluorodeoxyglucose uptake was detected. Conclusions: Presence of a focal colonic fluorodeoxyglucose uptake as an incidental finding on a positron emission tomography/computed tomography scan justifies a colonoscopy. Fluorodeoxyglucose uptake of adenomatous polyps increases in conjunction with the degree of dysplasia and adenoma size. Nevertheless, positron emission tomography/computed tomography has no place in colon cancer screening and surveillance.

Keywords: Positron emission tomography, fluorodeoxyglucose, polyp

ğu bildirilmiştir. Bu nedenle insidental saptanan fokal veya nodüler lezyonların kolonoskopik değerlendirilmesi önerilmektedir. Yazımızda bu karakterde olgular sunulmuştur.

\section{GEREÇ ve YÖNTEM}

Farklı bir malignite tanısı nedeniyle onkoloji kliniği takiplerinde yapilan PET incelemede fokal kolonik FDG tutulumu olan ve kolonoskopiye yönlendirilen hastalar çalışmaya alındı. Fokal tutulumlu toplam 6 adet (K:5, E:1) olgu dahil edildi. PET bulgularının etiyolojisi, gerekli hazırlık sonrası uygulanan total kolonoskopi ile kolonik lümen patolojileri araştırıldı. Saptanan tüm lezyonlara endoskopik polipektomi çıkarımı uygulandı. Lezyonların karakteri histopatolojik inceleme ile araştırılarak sunuldu. 

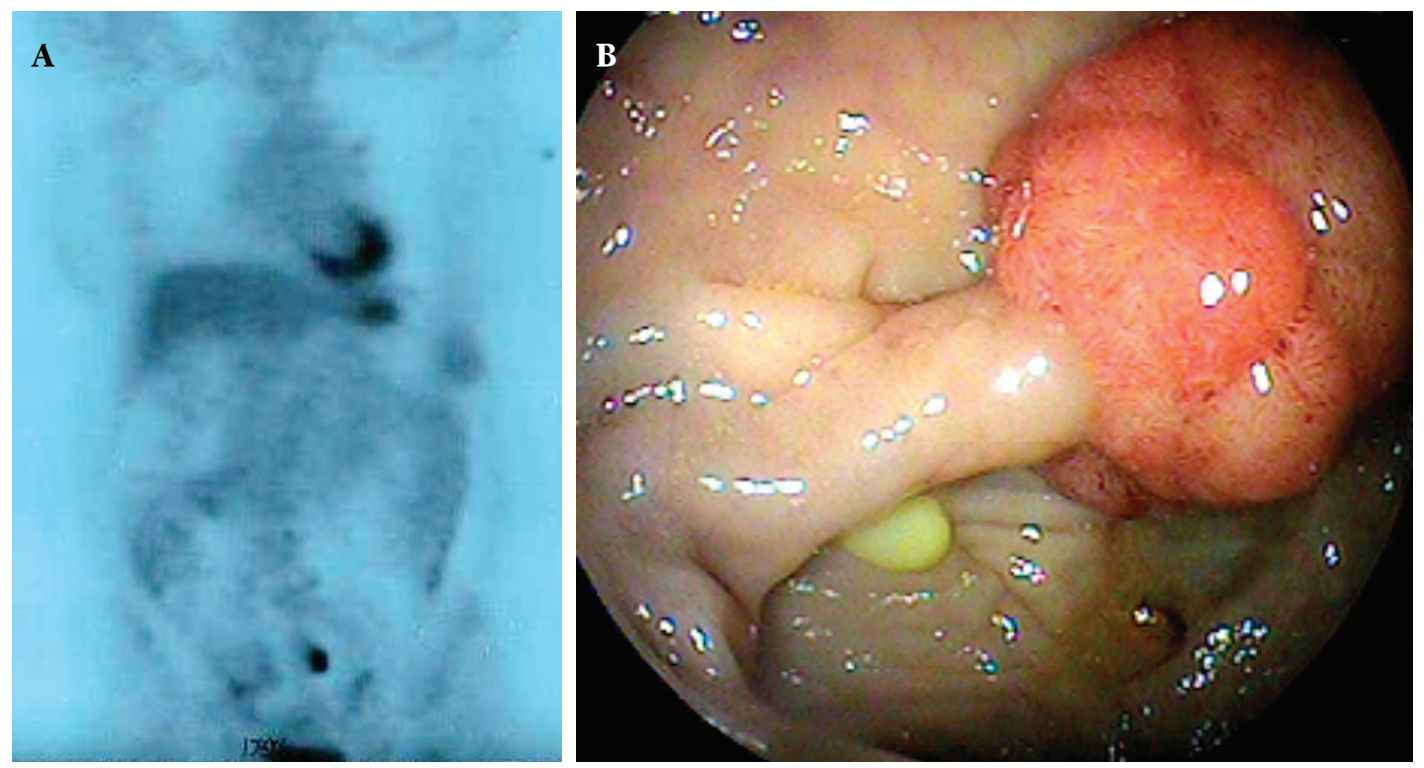

Resim 1 A. Sol kolonda fokal FDG tutulumu. B. Sigmoid kolonda polip.

Olgu I

Opere meme kanserli 62 yaşında kadın hastanın, 2 yıl önce radyoterapisi ve kemoterapisi tamamlanmıs. Takibinde PET'te pelviste kolon lokalizasyonunda artmış FDG tutulumu tespit edilmiştir. Kolonoskopide sigmoid kolonda $30 \mathrm{~mm}$ çaplı sapli polip tespit edildi. Polipektomi materyalinin histopatolojik değerlendirmesinde, tübülovillöz adenom tanısı aldı (Resim 1 A, B).

\section{Olgu II}

Prostat kanseri nedeniyle opere 68 yaşında erkek hastanın 3 yll önce medikal onkoloji tarafindan kemoterapisi tamamlanmış. Sırt ağrısı olan hastaya kemik metastazı şüphesi ile yapılan PET incelemede; splenik fleksurada lokal tutulum tespit edilerek tarafımıza dış merkezden refere edildi. Kolonoskopide inen kolonda $25 \mathrm{~mm}$ çapında sessil polipoid lezyon tespit edildi. Polipektomi materyalinin histopatolojisinde, adenomatöz polip tespit edildi.

\section{Olgu III}

Opere over kanseri olan 53 yaşındaki kadın hastaya karaciğer metastazı şüphesiyle çekilen PET'te çıkan kolonda yaklaşı 15 mm çapında hipermetabolik tutulum saptandı. Kolonoskopide $20 \mathrm{~mm}$ çapında sessil polip tespit edildi, histopatolojik değerlendirmede fokal yüksek dereceli displazi içeren adenomatöz polip tanısı aldı.

\section{Olgu IV}

Akciğer tüberkülozu nedeniyle 26 yll önce 8 ay antitüberküloz tedavi alan 56 yaşındaki kadın hastanın toraks bilgisayarlı tomografi (BT)'sinde sol akciğerde multipl 1,5 cm çaplı nodülleri nedeniyle çekilen PET'te sigmoid kolonda yaklaşı 20 mm çapinda hipermetabolik tutulum saptanmış. Kolonoskopide sigmoid kolonda saplı polip tespit edildi, histopatolojik değerlendirmede tubuler adenomatöz polip tanısı aldı.

Olgu V

Opere sigmoid kolon kanseri nedeniyle 6 yıldır takip edilen
59 yaşında kadın hastanın karaciğerinde kistik kitle nedeniyle yapilan PET'te transvers kolona lokalize artmış FDG tutulumu saptanmış. Kolonoskopide lokalizasyona uygun saplı $35 \mathrm{~mm}$ çaplarında polip görüldü. Histopatolojik değerlendirmede yüksek dereceli displazi içeren adenomatöz polip tanısı aldı (Resim 2 A-C).

\section{Olgu VI}

Opere meme kanserli 47 yaşındaki kadın hastanın yapılan metastaz taramasında transvers kolon distalinde $15 \mathrm{~mm}$ çapında fokal tutulum tespit edilmiş. Kolonoskopide PET ile aynı lokalizasyonda polipin histopatolojik değerlendirmesinde düşük dereceli displazili tübüler adenom saptandı.

\section{BULGULAR}

PET'de saptanan fokal tutulumlar kolonoskopi ile uyumluydu. Fokal tutuluma neden olan poliplerin tümünün çapı $\geq 15$ mm idi. Yüksek dereceli displazi içeren 4 polipin çapı $\geq 25$ $\mathrm{mm}$ idi. Diğer poliplerden biri $20 \mathrm{~mm}$ olup tübüler adenom, diğeri ise $15 \mathrm{~mm}$ olup düşük dereceli displazi saptandı. Tüm olguların ikisinde ek olarak 6-7 mm çapında toplam 5 adet adenomatöz polip saptandı. Bu 5 adet polipin histopatolojik değerlendirmesinde displazi yoktu. Bu poliplere uyan FDG tutulumu saptanmamıştı.

\section{TARTISSMA}

FDG-PET, lenfoma, malign melanom, akciğer ve kolon kanseri dahil olmak üzere çeşitli tümörlerin sıklıkla da orijini belirsiz metastazın primerinin tespiti ve uygulanan tedavilerin takibi için klinikte kullanmakta olduğumuz bir yöntemdir (1). Kolon patolojilerinde ise cerrahi sonrası kanser nüksünü veya metastazını tespit etmek için sıklıkla kullanılır. Klinikte etkin olarak kullanılan bu yöntemin, premalign kolon lezyonları veya erken evre kolon kanseri gibi durumlarda etkinliği ve duyarlılığı tam tanımlanmamıştır $(2,3)$. Birçok vaka serilerinde de FDG-PET'in büyük adenomların tespitinde faydalı olduğu bildirilmiştir. 


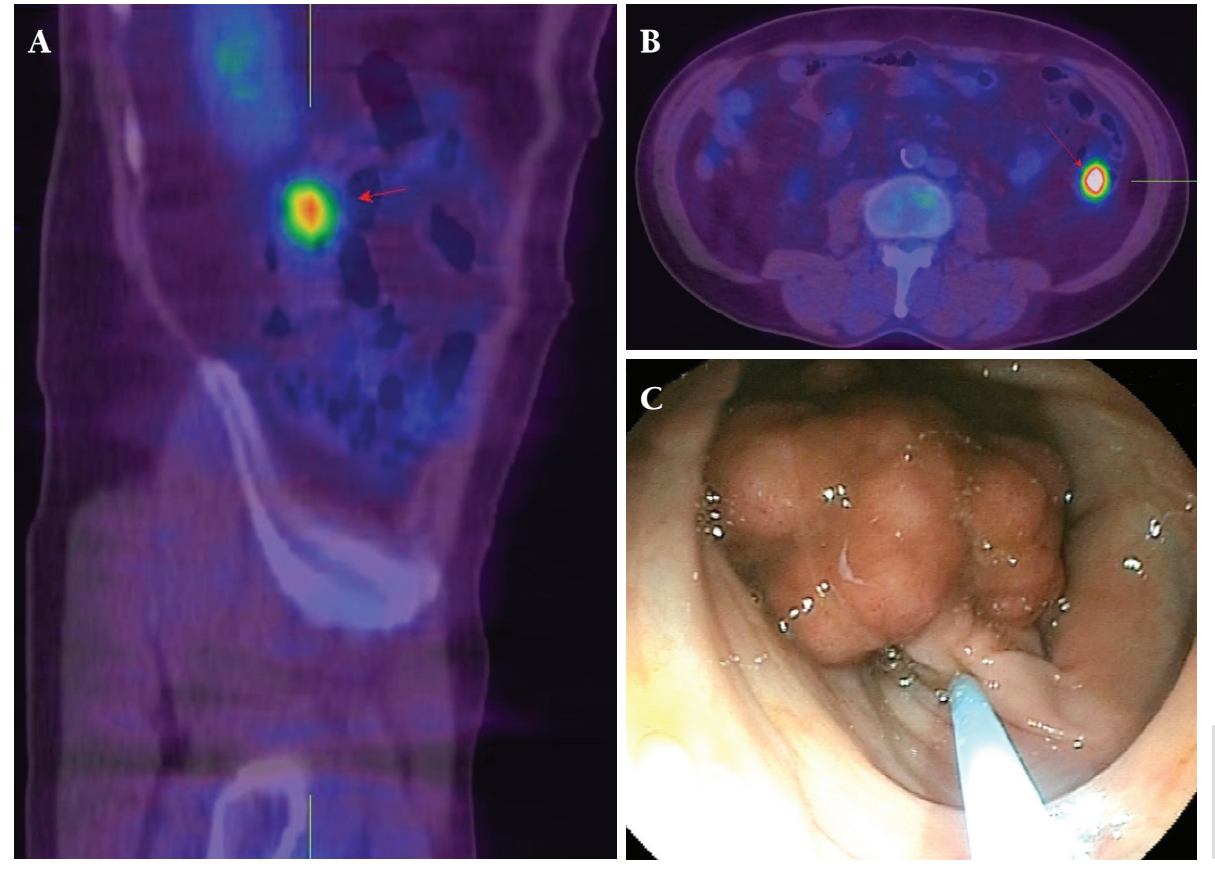

Resim 2 A. Transvers kolonda fokal FDG tutulumu. B. Fokal tutulumun transvers görünümü. C. Transvers kolonda polip
PET-BT ile FDG tutulum paterni genel olarak fokal tutulum (grup A), diffüz tutulum (grup B) ve tutulmama (grup C) olarak üç gruba ayrılmıştır (4).

Farklı yayınlarda PET-BT'de beklenmeyen kolonik FDG tutulumu ile neoplastik patolojinin sıklıkla ilişkili olduğu saptanmıştır. Özellikle proksimal kolonda fokal FDG tutulumunun neoplazm açısından pozitif prediktif değeri segmental tutulumlara göre daha yüksek bulunmuştur (5). Bizim 6 vakamızda da fokal FDG tutulumu distal kolonda olmasina rağmen lezyonların endoskopik lokalizasyonu ile uyumluydu. Sol kolonda saptanan fokal FDG tutulumu da patolojik olarak yorumlanmalıdır. Farklı bir çalışmada 10.978 hasta değerlendirilmiş ve 148 hastada kolonik FDG tutulumu tespit edilmiştir. Olguların \%23,5'inde kolorektal tümör, \%20,5'inde polip, diğer \%56'sında ise normal bulgular tespit edilmiş. Özellikle sağ kolondaki fokal FDG tutulumunun yanlış pozitiflik oranının yüksek olduğu da belirtilmiştir (6).

Kolonoskopi ile PET-BT bulgularını eşzamanlı karşılaştıran bir çalışmada; fokal tutulum paterni olan 123 polipin 9'u adenokarsinom, 6'sı yüksek dereceli displazi saptanmış. Bu tespitler 10 mm'den büyük poliplerde olup; FDG tutulumu adenomlarda ( $>10 \mathrm{~mm}$ ), adenokarsinomlara (>10 mm) göre daha az homojen tespit edilmiştir (7). Olgularımızın tümünde fokal FDG-PET tutulum ile kolonoskopik lokalizasyon uyumluydu. Ayrica tutuluma neden olan poliplerin tümünün çapı $\geq 15$ mm'di.

Retrospektif olarak pulmoner nodüllerin değerlendirildiği 500 olgunun incelenmesinde; 197 olgunun kliniğinde veya radyolojik incelemelerinde anormal gastrointestinal bulgu yok iken 59'unda PET-BT'de farklı kolonik segmentlerde yaygın tutulumlar saptanmış. Fokal tutulumlu 17 olgunun 5'inde ise kolon kanseri tespit edilmiş. Beklenmedik ekstratorasik tutulumun araştırılmasında saptanan insidental kolon kanserinin tedavi belirlenmesinde önemli ve çok düşük maliyetli olduğu vurgulanmıştır (8). Bizim olgularımızda da yüksek dereceli displazi içeren 4 polipin endoskopik lokalizasyon ile korele saptanması, ileri patolojiyi direkt işaret etmesi açısından fokal FDG tutulumunda PET-BT'nin etkinliğini göstermektedir.

FDG-PET çalışmalarında, yüksek FDG tutulumu gösteren 14 mm kadar küçük primer kolorektal kanserler tespit edilmiştir (9). Farklı bir çalışmada kolonoskopi ile karşılaştırıldığında PET'in sensitivitesi $\% 74$, spesifitesi $\% 84$, pozitif prediktif değeri \%78 saptanmıştır. PET inceleme 3-10 mm büyüklükteki 4 polipi atlamış. Anormal FDG birikimi olan 9 hastanın 4'ünde büyük adenomatöz polip, 2'sinde karsinom saptanmış, diğer 3'ünde ise lokalizasyona uyan lezyon saptanmamış. Yine FDG tutulumu ile endoskopi pozitif lezyonların lokalizasyonları arasında iyi bir korelasyon saptanarak kolorektal kanserli hastaların non-invaziv takibinde ve diğer kolonik lezyonların tesbitinde FDG-PET'in yararlı olduğu desteklenmiştir. Ayrıca FDG tutulumu derecesi ile adenomdaki displazi derecesi orantılı bulunmuştur $(10,11)$. Bunlara rağmen kanserli hastaların tüm vücut taramasında, FDG'nin inflamasyon ya da enfeksiyon bölgelerinde de biriktiği unutulmamalıdır. Bu durum enfeksiyonun metastazı taklit edebileceğinden zorluklara ve vücut taramasında spesifikliğin azalmasına neden olur (12). Bizim olgularımızda da displazili tüm olgular tespit edilmiştir. Olgularımızda PET ile saptanamayan 5 adet polipin çapı 6-7 mm idi. Bu 5 adet polipin histopatolojik değerlendirmesinde displazi yoktu ve lokalizasyona uyan FDG tutulumu saptanmamıştı. Çalışmayla uyumlu biçimde tespit edilmeyen poliplerin çapı $<10 \mathrm{~mm}$ idi.

Başka bir çalışmada kolonoskopi ve PET uygulanan 110 hastanın 30'unda 5-30 mm ebatlarında 59 polip saptanmış. Kolonoskopik saptanan 59 polipin \%24'ü PET ile saptanabilmiş. PET tutulumlu 10 vakanin 9'unda kolonoskopik olarak polip $>13 \mathrm{~mm}$ ve adenom karakterindeymiş. PET'in pozitifliğinin 
adenom boyutunun (>13 mm) büyümesiyle arttığı (\%90) saptanmış (13). Diğer çalışmada ise FDG-PET'in duyarlılığı adenomun boyutunun büyümesi (1-5 mm \%21, 6-10 mm $\% 47,>11 \mathrm{~mm} \% 72$ ) ve displazinin derecesinin artmasiyla da (düşük dereceli displazi \%33, yüksek dereceli displazi \%76, karsinom \%89) arttığı saptanmış (11). Bizim olgularımızda az sayıda ve farklı çaplardaki polipler içinde bu durum geçerlidir. Ayrıca displazili tüm olgularımızda FDG tutulumu tespit edilmiştir. Bunlara rağmen neoplastik olmayan lezyon (\%12) ve inflamasyon varlığında FDG tutulumunun olduğu ve yanlış pozitiflik (\%23) verebileceği hatırlanmalıdır $(4,6,14)$.

Günümüzde PET görüntüleme, yetersizlikleri nedeniyle yüksek riskli hastalarda kolonik adenom takibinde ve kanser sürveyansında önerilmemektedir. Kolondaki fizyolojik FDG tutulumu, yanlış pozitif sonuçlara yol açabileceği gibi, gerçek pozitif vakaları çevre dokudaki fizyolojik tutulumdan ayırt edememesi nedeniyle yanlış negatif değerlendirmelere de neden olabilmektedir (15).

Sonuç olarak kanser evrelemesinde ve sürveyansında non-invaziv olmasının avantajı ile giderek artan kullanıma ulaşan PET, çoğunlukla adenomatöz olan polipleri insidental olarak saptayabilmektedir. PET'te saptanan fokal tutulumlar kolonoskopik lokalizasyon ile uyumlu bulunmaktadır. Insidental fokal PET tutulumlu vakalarımızda adenomatöz, displazi içeren ve boyutu $\geq 15 \mathrm{~mm}$ polipler saptand. Insidental tespit edilen fokal hipermetabolik durumlar göz ardı edilmeyerek; teyidi ve çıkarılması için kolonoskopik inceleme uygulanmalıdir.

\section{KAYNAKLAR}

1. Bomanji JB, Costa DC, Ell PJ. Clinical role of positron emission tomography in oncology. Lancet Oncol. 2001;2:157-64.

2. Macbeth RA, Bekesi JG. Oxygen consumption and anaerobic glycolysis of human malignant and normal tissue. Cancer Res 1962;22:244-8.

3. Chen YK, Kao CH, Liao AC, et al. Colorectal cancer screening in asymptomatic adults: the role of FDG PET scan. Anticancer Res 2003;23:435761.

4. Roh SH, Jung SA, Kim SE, et al. The clinical meaning of benign colon uptake in 18 F-FDG PET: Comparison with colonoscopic findings. Clin Endos. 2012;45:145-50.

5. Lee JC, Hartnett GF, Hughes BG, et al. The segmental distribution and clinical significance of colorectal fluorodeoxyglucose uptake incidentally detected on PET-CT. Nucl Med Commun 2009;30:333-7.

6. Peng J, He Y, Xu J, et al. Detection of incidental colorectal tumours with 18F-labelled 2-fluoro-2-deoxyglucose positron emission tomography/ computed tomography scans: results of a prospective study. Colorectal Dis 2011;13:e374-8.

7. Shim JH, O JH, Oh SI, et al. Clinical significance of incidental colonic 18F-FDG uptake on PET/CT images in patients with gastric adenocarcinoma. J Gastrointest Surg 2012;16:1847-53.

8. Zhuang H, Hickeson M, Chacko TK, et al. Incidental detection of colon cancer by FDG positron emission tomography in patients examined for pulmonary nodules. Clin Nucl Med 2002;27:628-32.

9. Yasuda S, Ide M, Takagi S, et al. F-18 FDG uptake in colonic adenoma. Clin Nucl Med 1998;23:99-100.

10. Drenth JP, Nagengast FM, Oyen WJ. Evaluation of (pre-)malignant colonic abnormalities: endoscopic validation of FDG-PET findings. Eur J Nucl Med 2001;28:1766-9.

11. van Kouwen MC, Nagengast FM, Jansen JB, et al. 2-(18F)-fluoro-2-deoxy-D-glucose positron emission tomography detects clinical relevant adenomas of the colon: A prospective study. J Clin Oncol 2005;23:3713-7.

12. Bakheet SM, Saleem M, Powe J, et al. F-18 fluorodeoxyglucose chest uptake in lung inflammation and infection. Clin Nucl Med 2000;25:273-8.

13. Yasuda S, Fujii H, Nakahara T, et al. 18F-FDG PET detection of colonic adenomas. J Nucl Med 2001;42:989-92.

14. Treglia G, Calcagni ML, Rufini V, et al. Clinical significance of incidental focal colorectal (18)F-fluorodeoxyglucose uptake: our experience and a review of the literature. Colorectal Dis 2012;14:174-80.

15. Yasuda S, Takahashi W, Takagi S, et al. Factors influencing physiological FDG uptake in the intestine. Tokai J Exp Clin Med 1998;23:241-4. 